\title{
AN IN VIVO STUDY TO COMPARE THE MARGINAL FIT ACCURACY OF CROWNS PREPARED USING TWO DIFFERENT MATERIALS
}

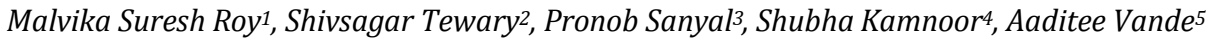

1 Postgraduate Student, Department of Prosthodontics, School of Dental Sciences, KIMSDU, Karad, Maharashtra, India.

${ }^{2}$ Reader, Department of Prosthodontics, School of Dental Sciences, KIMSDU, Karad, Maharashtra, India.

3 Professor and HOD, Department of Prosthodontics, School of Dental Sciences, KIMSDU, Karad, Maharashtra, India.

${ }_{4}^{4}$ Reader, Department of Prosthodontics, School of Dental Sciences, KIMSDU, Karad, Maharashtra, India.

${ }^{5}$ Postgraduate Student, Department of Prosthodontics, School of Dental Sciences, KIMSDU, Karad, Maharashtra, India.

\section{ABSTRACT}

\section{BACKGROUND}

Although the metal-ceramic system is still widely used to fabricate crowns and fixed partial dentures, and is considered as the standard treatment in dentistry, aesthetic concerns have stimulated the development of new dental tooth-coloured systems such as PEEK. So, the present study was planned to check the marginal fit accuracies of conventional Porcelain Fused to Metal (PFM) crowns and Polyether Ether Ketone (PEEK) crowns.

\section{METHODS}

Based on the inclusion and exclusion criteria, sample size of 80 patients was considered. Out of 80 patients, 40 patients (Group I) received PFM crowns and 40 patients received PEEK (Group II) crowns. The marginal fit accuracy of crowns was checked using stereomicroscope. CBCT of the same patient with the crown was made to validate the readings obtained using stereomicroscope.

\section{RESULTS}

Data was analysed with the SPSS (Statistical Package for Social Sciences) version 17. Comparison of the two groups for marginal gap was done with unpaired ' $t$ ' Test. For all the above tests, $p$ value is considered statistically significant when it was $\leq 0.05$. Four points were considered to measure the marginal gaps i.e., MB (Mesiobuccal), ML (Mesiolingual), DB (Distobuccal), DL (Distolingual). The highest marginal gap in the group I was at Mesiobuccal (MB) point i.e. 120.280000 microns and lowest marginal gap was at Distolingual (DL) point i.e. 110.127050 microns. It can be noted from CBCT that the marginal gap present in PFM crown is much greater than the PEEK crown.

\section{CONCLUSIONS}

Comparing the marginal fit accuracy between PFM and PEEK crowns based on the stereomicroscope readings, the marginal fit accuracy in PEEK crowns were much higher than the PFM crowns.

\section{KEY WORDS}

Marginal Fit, PFM, PEEK, Marginal Gap, Stereomicroscope

HOW TO CITE THIS ARTICLE: Roy MS, Tewary S, Sanyal P, et al. An in vivo study to compare the marginal fit accuracy of crowns prepared using two different materials. J. Evolution Med. Dent. Sci. 2019;8(24):1930-1934, DOI: 10.14260/jemds/2019/424

\section{BACKGROUND}

In a traditional Porcelain Fused to Metal (PFM) crown, the strength is provided by the metal substructure, and a porcelain veneer provides aesthetics. ${ }^{1}$ Porcelain fused to metal (PFM) crowns are used to restore badly broken-down teeth to protect remaining tooth structure. It may also be responsible for maintaining occlusion and providing aesthetics. ${ }^{2}$ Margins are unacceptable, if the gap between margins of the crown and tooth structure is greater than 50 um allowing insertion of the tip of the explorer inside. ${ }^{3}$ Marginal gap between the crown and the tooth may lead to microleakage and secondary caries. Secondary caries beneath crown margins is considered the most frequent reason for failure of crowns and fixed prosthodontic treatment. 4,5

'Financial or Other Competing Interest': None.

Submission 17-04-2019, Peer Review 03-06-2019,

Acceptance 10-06-2019, Published 17-06-2019.

Corresponding Author:

Dr. Malvika Suresh Roy,

Postgraduate Student,

Department of Prosthodontics, School of Dental Sciences,

KIMSDU, Karad-415110, Maharashtra, India.

E-mail: malvika.roy1@gmail.com

DOI: $10.14260 /$ jemds/2019/424

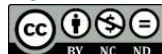

Poor marginal adaptation of ceramic crowns can result in damage to the tooth, periodontal tissues and the restoration. Large marginal discrepancies result in dissolution of the luting agent and favor micro leakage of bacteria and their byproducts. As a consequence, the tooth becomes more susceptible to inflammation of the vital pulp (post-operative sensitivity), secondary caries and marginal discoloration. The dental fraternity is yet to come to a consensus on what constitutes an acceptable marginal discrepancy (MD). A marginal gap (MG) ranging from 10 to $500 \mu \mathrm{m}$, with mean values from 50 to $100 \mu \mathrm{m}$, has been defined as acceptable. Marginal openings ranging from 50 to $120 \mu \mathrm{m}$ are considered to be clinically acceptable in terms of longevity. For CAD/CAM restorations, the generally acceptable MG discrepancies are between 50 and $100 \mu \mathrm{m}$.

Polyether ether ketone (PEEK) is a synthetic, tooth coloured polymeric material that has been used as a biomaterial in orthopaedics for many years. The monomer unit of ether ether ketone monomer polymerizes via stepgrowth dialkylation reaction of bis-phenolates to form polyether ether ketone. A common synthesis route for PEEK is the reaction between 4,40 -difluoro benzophenone and the disodium salt of hydroquinone in a polar solvent such as diphenyl sulphone at 300 8C. It is a semicrystalline material 
having a melting point around 335 8C. PEEK can be modified either by the addition of functionalized monomers (prepolymerization) or post-polymerization modifications by chemical processes such as sulphonation, amination and nitration. 6

According to Wolff's Law, the bone remodels according to the load that has been applied to it. Stress shielding is the reduction in volume of the bone around an implant due to the shielding of normal loads by the implant. Finite-element analysis (FEA) of carbon-fiber reinforced PEEK (CFR-PEEK) implants suggested that they could induce lesser stress shielding than titanium. ${ }^{7}$ However, since PEEK dental implants have not been used widely clinically, it is unknown if there is a difference between the bone resorption around PEEK and titanium implants in human subjects. Moreover, a more recent FEA study by Sarot et al. suggests there is no difference between the stress distribution around PEEK and titanium dental implants. Indeed, more clinical trials are vital to conclude whether or not PEEK implants produce lesser stress-shielding than titanium implants.

Although the metal-ceramic system is still widely used to fabricate crowns and fixed partial dentures and is considered as the standard treatment in dentistry, aesthetic concerns have stimulated the development of new dental tooth-colored systems as PEEK. PEEK is $20 \%$ ceramic reinforced, semicrystalline, thermoplastic and radiolucent polymer for extreme durability especially for frameworks for fixed and removable dental prostheses. It has many advantages as low density, light weight, shock absorber, biocompatible and venerable with composite resin. Biocompatibility, low plaque affinity, good aesthetics and characteristics close to dental structure are essential to modern materials used in advanced dentistry 8. Materials used for fixed partial dentures (FPDs) have evolved over the years. ${ }^{9}$ Any misfit of prosthesis, may result in microleakage, followed by caries, inflammation and periodontal diseases ${ }^{10-13}$

So, the present study was planned to check the marginal fit accuracies of conventional Porcelain fused to metal (PFM) crowns and Polyether Ether Ketone (PEEK) crowns.

\section{METHODS}

It was an experimental, analytical study, conducted among sample size of 80 patients based on the inclusion and exclusion criteria were enrolled in the present study. The universal convenient sampling method was used to draw the sample size. The study was conducted after obtaining ethical approval from the institutional ethical committee. All the cases were enrolled in the present study after obtaining their written consents.

Amongst 80 patients, Randomization was carried out and 40 patients were allocated to Group I receiving Porcelain fused to metal crowns (PFM) and group II consisted of 40 patients receiving Polyether ether ketone (PEEK) crowns. Consented patients requiring the fixed dental prostheses reporting to the OPD were considered for the study. Standardisation of tooth preparation procedure was obtained by uniform reduction occlusal reduction of $1.5 \mathrm{~mm}$; axial reduction of $1 \mathrm{~mm} ; 1.0-\mathrm{mm}$ wide 360 。 rounded shoulder located $0.5 \mathrm{~mm}$ supragingivally, following the principles of tooth preparation. Following the preparation, cementation for the prostheses was done. After 7 days, marginal fit of the crown was checked. A customized tray for buccal and lingual surface of a molar was fabricated using cold cure acrylic. Poly-vinyl siloxane impression (3M IMPREGUM) was used to record the marginal gap between the finish line of tooth preparation and crown obtained. A total of four points was taken for each tooth; two buccally (MB-mesiobucally, DBdistobucally) and two lingually (Mesiolingually-ML, distobucally-DL). These points were focused under the stereomicroscope under 45X resolution. The average of these points was taken. Thus, the vertical distance (Marginal Gap) between the prepared tooth and crown was obtained.

\section{Statistical Analysis}

The data was collected with the help of pre-validated, semistructured, standardised case record proforma. Data were entered in to Microsoft Excel 2010 and the data was analysed with the SPSS (Statistical package for Social Sciences) version 17 software. CBCT of the same patient with the crown were made to validate the readings obtained using stereomicroscope. The data was arranged in tables and graphs for frequency analysis. Parameters of central tendency and modes of dispersion were studied. Mean, standard deviation were calculated.

\section{RESULTS}

The present experimental, analytical study was conducted in a tertiary health centre to check the marginal fit accuracies of conventional Porcelain fused to metal (PFM) crowns and Polyether Ether Ketone (PEEK) crowns. Amongst 80 patients, Randomization was carried out and 40 patients were allocated to Group I receiving Porcelain fused to metal crowns (PFM) and group II consisted of 40 patients receiving Polyether ether ketone (PEEK) crowns.

In the present study, it was found that the highest marginal gap in the group I (PFM) was at Mesiobuccal (MB) point i.e. 120.280000 microns and lowest marginal gap was at Distolingual (DL) point C i.e. 110.127050 microns (Table 1) (Chart 1). In the group II (PEEK), highest marginal gap was at mesiolingual point i.e. 90.7416250 microns and lowest marginal gap was at distobuccal point i.e. 89.5456250 microns (Table 2) (Chart 2). CBCT of the same patient with the crown were made to validate the readings obtained using stereomicroscope (Test report 1 ).

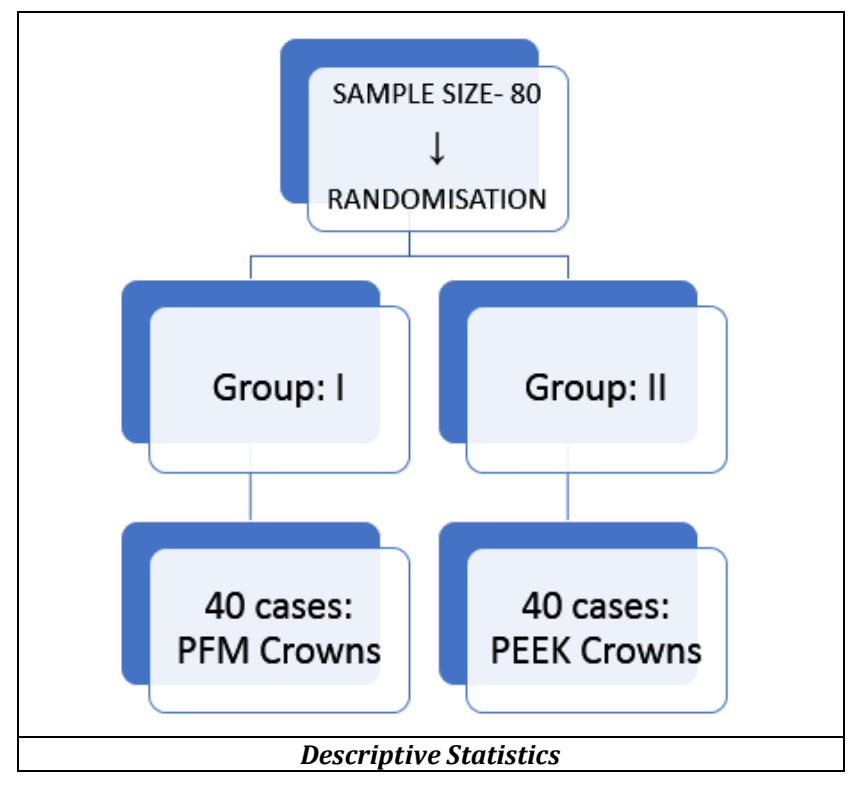




\begin{tabular}{|c|c|c|c|c|c|c|}
\hline Group & $\begin{array}{l}\text { Four } \\
\text { Sites }\end{array}$ & $\mathbf{N}$ & $\underset{(\mu \mathrm{m})}{\operatorname{Minimum}}$ & $\underset{(\mu \mathrm{m})}{\operatorname{Maximum}}$ & $\begin{array}{c}\text { Mean } \\
(\mu \mathrm{m})\end{array}$ & $\begin{array}{c}\text { Std. } \\
\text { Deviation } \\
(\sigma)\end{array}$ \\
\hline \multirow{4}{*}{$\begin{array}{l}\text { Group } \\
\text { I } \\
(\mathrm{PFM})\end{array}$} & $\mathrm{MB}$ & 40 & 111.500000 & 125.780000 & 120.280000 & 3.280761325 \\
\hline & ML & 40 & 111.500000 & 125.780000 & 119.944500 & 3.205444847 \\
\hline & $\overline{\mathrm{DB}}$ & 40 & 107.450000 & 112.550000 & 110.136800 & 1.606514482 \\
\hline & DL & 40 & 107.450000 & 112.780000 & 110.127050 & 1.640855498 \\
\hline \multicolumn{7}{|c|}{ Table 1. Descriptive Statistics for Group I (PFM) } \\
\hline \multicolumn{7}{|c|}{$\begin{array}{c}\text { MB- Mesiobuccal, ML- Mesiolingual, DB- Distobuccal, DL- Distolingual; } \\
\mu \mathrm{m} \text { - Micrometre }\end{array}$} \\
\hline
\end{tabular}

\begin{tabular}{|c|c|c|c|c|c|c|}
\hline \multicolumn{7}{|c|}{ Descriptive Statistics } \\
\hline Group & $\begin{array}{l}\text { Five } \\
\text { Sites }\end{array}$ & $\mathbf{N}$ & $\begin{array}{l}\text { Minimum } \\
(\mu \mathrm{m})\end{array}$ & $\begin{array}{l}\text { Maximum } \\
(\mu \mathrm{m})\end{array}$ & $\begin{array}{l}\text { Mean } \\
(\mu \mathrm{m})\end{array}$ & $\begin{array}{c}\text { Std. } \\
\text { Deviation } \\
(\sigma)\end{array}$ \\
\hline \multirow{4}{*}{$\begin{array}{c}\text { Group } \\
\text { II } \\
\text { (PEEK) }\end{array}$} & MB & 40 & 87.650000 & 92.540000 & 90.3021250 & 1.250559304 \\
\hline & ML & 40 & 87.650000 & 92.780000 & 90.7416250 & 1.117386137 \\
\hline & DB & 40 & 86.580000 & 91.650000 & 89.5456250 & 0.979465571 \\
\hline & $\mathrm{DL}$ & 40 & 86.580000 & 91.650000 & 89.5541250 & 0.979825264 \\
\hline \multicolumn{7}{|c|}{ Table 2. Descriptive Statistics for Group II (PEEK) } \\
\hline \multicolumn{7}{|c|}{$\begin{array}{c}\text { MB- Mesiobuccal, ML- Mesiolingual, DB- Distobuccal, DL- Distolingual; } \\
\mu \mathrm{m} \text { - micrometre }\end{array}$} \\
\hline
\end{tabular}
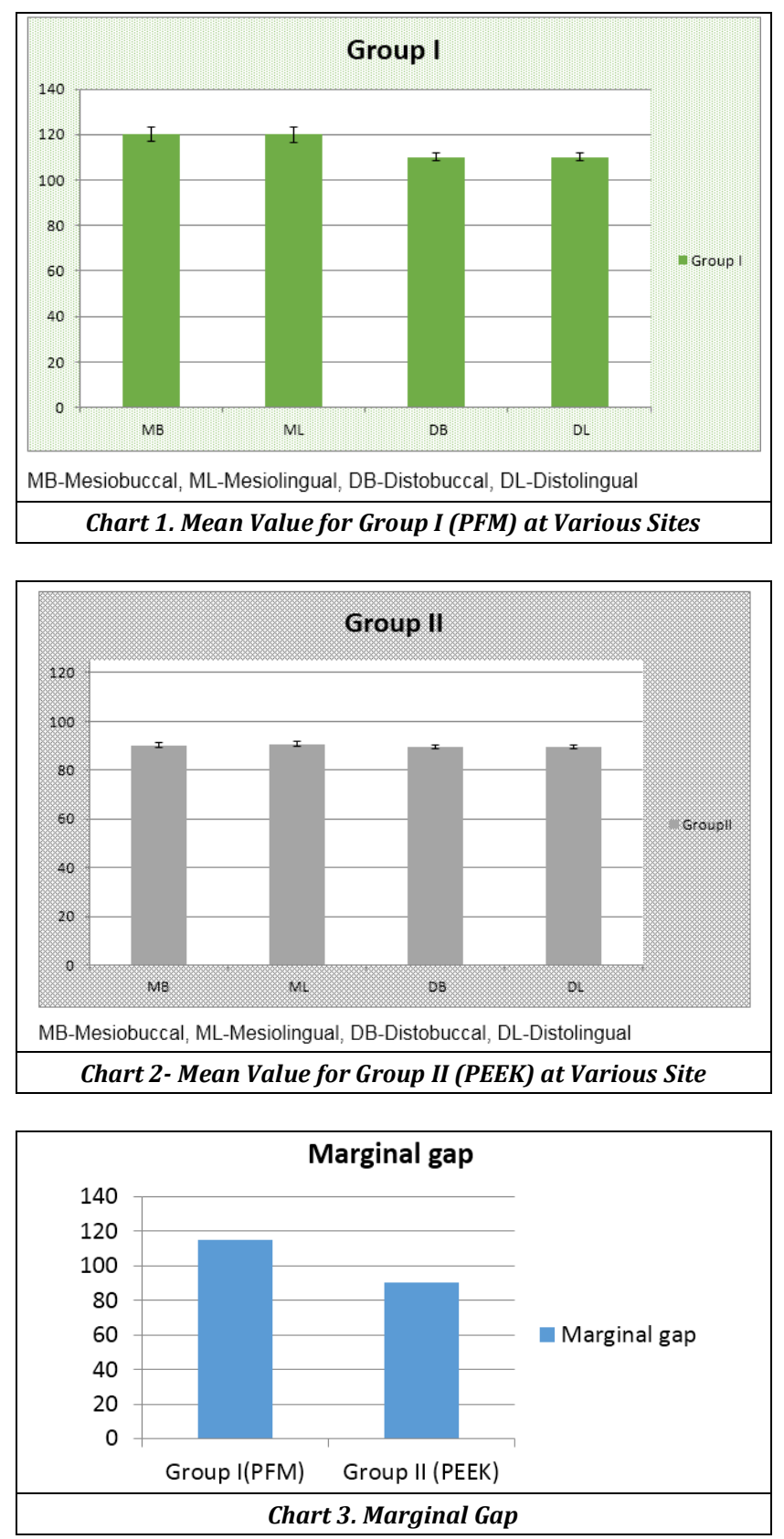

\section{DISCUSSION}

Fixed dental prostheses (FDPs) have been always the benchmark for replacement of missing teeth as these improve patient's comfort, masticatory ability, and patient's selfimage ${ }^{14}$. Precise seating and fitting of the prostheses are essential to fulfil the principles of restorations. Marginal fit and internal fit both depend on the clinical and laboratory steps. Marginal fit is a very important factor to be considered for the success of crowns. ${ }^{15}$ If the marginal fit is not proper, it results in increased plaque accumulation, gingival sulcular fluid flow, bone loss, resulting in microleakage, followed by recurrent caries, periodontal disease and eventually affecting the longevity of prosthetic restorations. ${ }^{16}$ According to Rodiger $\mathrm{M}$ et al, restorative material has an influence on the marginal fit accuracy of the crowns. ${ }^{17}$ Keeping this in mind, the present study was considered. Materials used for fixed dental prostheses have several properties of strength, durability and most important of all is biocompatibility. Till date there has been several materials used. It includes alloys, ceramics, and high-performance polymers such as zirconia, $\mathrm{Ni}-\mathrm{Cr}$, lithium disilicate, and so on. There has been always a search for a better material which fulfils the biomechanical principles of restorations. One such material which has made its invasion into dentistry is polyether ether ketone (PEEK). Due to its excellent stability, its optimal polishing properties and its low plaque affinity, BioHPP is very good for precise prosthetic restorations fabrication. Considering the advantages and the properties of the PEEK material, this material was considered in the present study. Marginal fit is an important factor to be considered in any fixed prostheses. In addition, PEEK being a newer material with better biomechanical properties; PEEK (BioHPP) was compared with the conventional PFM crowns. Also, the literature is limited to comparison between pressable techniques and lost wax technique.

In the inclusion criteria, patients requiring full veneer crowns were considered .The age group of 18-45 years was considered, considering the health of hard and soft tissues. As the present study required supragingival margin placement, hence it was decided to include molars for aesthetic reasons in the study.

\section{Clinically Acceptable Level of Marginal Gap}

According to Goldin EB et al., marginal discrepancy in the range of 40-120 microns is considered clinically acceptable for the success of the crowns. ${ }^{18}$ According to McLean and von Fraunhofer., the clinically acceptable marginal gap should be within 120 microns. ${ }^{19}$ Sakrana $\mathrm{AA}^{20}$ conducted a study where the marginal gap was in the range 25 to 40 microns for cemented restorations and was considered a clinical goal.

\section{Sectioning of Samples}

In the present study a customized tray with handle for buccal and lingual surface of a molar was fabricated using cold cure acrylic (DPI). Tray (buccal and lingual) was prepared for making the marginal impression of buccal and lingual surface of PFM and PEEK crowns with polyvinyl-siloxane impression material. The sectioned poly-vinyl siloxane impression material was focused under stereomicroscope under 45X.

Considering the two groups, it was found that the marginal gap was higher in group I (PFM) compared to the group II (PEEK) (Chart 3). In group it was highest at the 
mesiobuccal point and in group II it was highest at the mesiolingual point. The two groups which were considered in our study was one fabricated by lost wax technique and the other fabricated using pressable technique. Most of the comparison in the literature is between systems themselves ie. pressable technique, lost wax technique, CAD-CAM etc. Also according to Boeckler et al, crowns from different alloys and technologies showed differences in marginal fit.21 Boeckler et al used Crowns made from different alloys and technologies showed partly significantly $(p<0.05)$ different marginal gaps (Mean ranging from 35 micron to 92 micron) and significantly $(\mathrm{p}<0.05)$ different overextended margins (Mean ranging from 40 micron to 149 micron). There were significant correlations $(\mathrm{p}<0.05)$ between subjective findings and objective data. Significant correlations $(\mathrm{p}<0.01)$ were also found between the subjective findings of dentists and technicians. Compared to the marginal gap, only the overextended margin had a significant influence $(\mathrm{p}=0.00)$ on the subjective evaluations of the clinicians.

According to Nawafleh NA et al, there was a substantial lack of consensus relating to marginal adaptation of various crown systems due to differences in testing methods and experimental protocols employed. Direct view technique was the most commonly used method of reproducible results. Also, conducting an experimental set-up of testing a minimum of 30 specimens at 50 measurements per specimen should produce reliable results. Additionally, using a combination of two measurement methods can be useful in verification of results 22

According to literature, there are various methods for measurement of marginal gaps. ${ }^{22}$ Direct view method, Impression replica technique, Cross-sectional technique and Profilometry. Combination of various methods have been used in the present study. According to Byrne $G$, the cemented or uncemented crowns have an influence on the marginal gap measurement. ${ }^{23}$ In the present study considering all the above factors, the marginal gap was assessed after 7 days of cementation.

\section{CONCLUSIONS}

Within the limitations of the study, following conclusions were drawn-

1. Comparing the marginal fit accuracy between PFM and PEEK crowns based on the stereomicroscope readings, the marginal fit accuracy in PEEK crowns was much higher than the PFM crowns.

2. The readings obtained were validated with CBCT, and it was found that the marginal gap in PFM crowns was much higher than the PEEK crowns.

\section{REFERENCES}

[1] Etman MK, Woolford MJ. Three-year clinical evaluation of two ceramic crown systems: a preliminary study. J Prosthet Dent 2010;103(2):80-90.

[2] Ikai H, Kanno T, Kimura K. A review of clinical followup studies focusing on pre-treatment conditions of abutment and clinical examination parameters. Nihon Hotetsu Shika Gakkai Zasshi 2006;50(2):245-55. (Japanese).

[3] Jalalian E, Jannati H, Mirzaei M. Evaluating the effect of a sloping shoulder and a shoulder level on the marginal integrity of porcelain-fused-to-metal (PFM) veneer crowns. J Contemp Dent Pract 2008;9(2):1724.

[4] Rosenstiel SF, Land MF, Fujimoto J. Contemporary fixed prosthodontics. $4^{\text {th }}$ edn. St. Louis: Mosby 2006.

[5] Zoellner A, Heuermann M, Weber HP, et al. Secondary caries in crowned teeth: correlation of clinical and radiographic findings. J Prosthet Dent 2002;88(3):314-9.

[6] Staniland PA, Wilde CJ, Bottino FA, et al. Synthesis, characterization and study of the thermal properties of new polyarylene ethers. Polymer 1992;33(9):197681.

[7] Lee WT, Koak JY, Lim YJ, et al. Stress shielding and fatigue limits of poly-ether-ether-ketone dental implants. J Biomed Mater Res Part B: Appl Biomater 2012;100(4):1044-52.

[8] Kurtz SM, Devine JN. PEEK Biomaterials in Trauma, Orthopaedic and Spinal Implants. Biomaterials 2007;28(32):4845-69.

[9] Oral Health / WHO. http://www. who.int/ mediacentre /factsheets/fs318/en/accessed on 14/11/2017.

[10] Monich PR, Berti FV, Porto LM, et al. Physicochemical and biological assessment of PEEK composites embedding natural amorphous silica fibers for biomedical applications. Mater Sci Eng C Mater Biol Appl 2017;79:354-62.

[11] Najeeb S, Zafar MS, Khurshid Z, et al. Applications of Poly ether ether ketone (PEEK) in oral implantology and prosthodontics. J Prosthod Res 2016;60(1):12-9.

[12] Vaezi M, Yang S. A novel bioactive PEEK/HA composite with controlled 3D interconnected HA network. Int J Bioprint 2015;1:66-76.

[13] Zoidis P, Papathanasiou I, Polyzois G. The use of a modified Poly-Ether-Ether-Ketone (PEEK) as an alternative framework material for removable dental prostheses. A clinical report. J Prosthodont 2016;25(7):580-4.

[14] Harish V, Ali SAM, Jagadesan N, et al. Evaluation of internal and marginal fit of two metal ceramic system - in vitro study. Journal of Clinical and Diagnostic Research 2014;8(12):ZC53-6.

[15] Sakrana AA. In vitro evaluation of the marginal and internal discrepancies of different esthetic restorations. J Appl Oral Sci 2013;21(6):575-80.

[16] Buso L, Higert E, Neisser MP, et al. Marginal fit of electroformed copings before and after the coction of the porcelain. Braz J Oral Sci 2004;3(8):409-13.

[17] Rodiger M, Schneider L, Rinke S. Influence of material selection on the marginal accuracy of CAD/CAMfabricated metal- and all-ceramic single crown copings. Article ID 2143906, BioMed Research International 2018;2018:1-8.

[18] Goldin EB, Boyd NW 3rd, Goldstein GR, et al. Marginal fit of leucite-glass pressable ceramic restorations and ceramic-pressed-to-metal restorations. J Prosthet Dent 2005;93(2):143- 7.

[19] McLean JW, Von Fraunhofer JA. The estimation of cement film thickness by an in vivo technique. Br Dent J 1971;131(3):107-11. 
[20] Pera P, Gilodi S, Bassi F, et al. In vitro marginal adaptation of alumina porcelain ceramic crowns. J Prosthet Dent 1994;72(6):585-90.

[21] Boeckler AF, Stadler A, Setz JM. The significance of marginal gap and overextension measurement in the evaluation of the fit of complete crowns. J Contemp Dent Pract 2005;6(4):26-37.
[22] Nawafleh NA, Mack F, Evans J, et al. Accuracy and reliability of methods to measure marginal adaptation of crowns and FDPs: a literature review. J Prosthodont 2013;22(5):419-28.

[23] Byrne G. Influence of finish-line form on crown cementation. Int J Prosthodont 1992;5(2):137-44. 